\title{
ESPECTÁCULO, PUBLICIDAD E IMAGEN: EL DESARROLLO DE LOS CENTROS DE BODYBUILDINGS EN AFGANISTÁN
}

\section{ENTERTAINMENT, ADVERTISING AND IMAGE: THE DEVELOPMENT OF BODYBUILDING CENTERS IN AFGHANISTAN}

\author{
Alejandra Val Cubero*
}

\section{RESUMEN}

El objetivo de este artículo es analizar los carteles de bodybuilding en Afganistán, porque nos permiten comprender ciertos cambios sociales que están teniendo lugar en el país y son una de las representaciones visuales que más se repite, junto con la publicidad de los salones de boda, de banca y de telefonía móvil. Partiendo de los presupuestos de la sociología visual, la metodología utilizada ha sido el análisis de más de doscientos carteles. La aparición de los centros de bodybuilding anuncia el germen de un nuevo tipo de sociedad que trata de combinar las tradiciones del pueblo afgano con las ideas, los productos y servicios llegados desde el exterior, impulsando un creciente interés del culto al cuerpo y una cierta concepción individualista y narcisista del individuo.

PALABRAS CLAVE: AFGANISTÁN * JUVENTUD * PUBLICIDAD * CARTEL * CULTURISMO

\section{ABSTRACT}

The aim of this article is to analyze the bodybuilding billboards in Afghanistan, because they allow us to understand certain social changes taking place in the country. These posters are one of the most widespread visual representations along with advertisements of wedding halls, banking and mobile telephony. Based on visual sociology, the methodology used was the study of over two hundred posters. The emergence of these bodybuilding centers announces the rise of a new type of society that tries to combine the traditions of the Afghan people with the ideas, products and services coming from abroad and encouraging a growing interest in body cult and a certain individualistic and narcissistic perception of the individual.

KEYWORDS: AFGHANISTAN * YOUTH * ADVERTISEMENT * BILLBOARD * BODYBUILDING

\footnotetext{
* Departamento de Periodismo y Comunicación Audiovisual de la Universidad Carlos III de Madrid, España.
} alejandra.val@uc3m.es 


\section{INTRODUCCIÓN}

Durante mi estancia en Afganistán en el año 2006 y parte del 2007, uno de los múltiples interrogantes que se me plantearon fue el número cada vez mayor de locales dedicados al entrenamiento físico y conocidos bajo el nombre en inglés de bodybuildings. Estos lugares reservados al público masculino se publicitan con fotos y dibujos de hombres extremadamente musculados y desnudos, en poses que recuerdan a las estatuas griegas por su contención y en muchos casos, su agresividad. Una de las intenciones de este artículo tratar de comprender la proliferación y el desarrollo de estos centros deportivos en la última década en Afganistán, partiendo de la hipótesis que los carteles de bodybuildings en este país van a permitir entender con más claridad las transformaciones sociales que están viviendo los jóvenes de clase media alta afgana, que se debaten entre la práctica de las tradiciones y la búsqueda de nuevas prácticas de relación y consumo.

El bodybuilding no es un deporte de origen afgano; el deporte que define a este pueblo es el buzkashi, practicado en todo Asia Central desde Kirguistan, Tayikistán hasta Uzbekistán, el cual consiste en apoderarse de un trozo de cabra o ternero que está en la tierra y conducirlo al galope a un lugar señalado, este se caracteriza por ser una práctica colectiva. El historiador Whitney Azoy en su libro Buzkashi. Game and power in Afghanistan, ha analizado esta práctica desde un punto de vista sociológico y antropológico, describiendo cómo es un deporte especialmente duro, ya que los partidos suelen durar varios días y no solo se pone en juego la victoria de uno u otro equipo, sino también el triunfo de una etnia sobre otra $y$ de una comunidad sobre otra (Azoy, 1985). Ante la dureza de este deporte que necesita de amplios espacios y de ágiles caballos que hay que mantener y cuidar, las jóvenes generaciones de clase media alta — que son una élite en el panorama social del país prefieren acudir a los gimnasios $y$ desarrollar su musculatura, caracterizado por ser una actividad mucho más individualista $y$ centrada en el culto al cuerpo.

Los autores que han estudiado la práctica de bodybuilding, destacan que su origen se remonta a principios del siglo XIX en los Estados Unidos, donde el entrenamiento metódico, continuo y repetitivo junto con una determinada alimentación y cuidado corporal -descanso a determinadas horas, series progresivas... - incrementaba la fortaleza física $y$ el músculo exagerado de aquellos que lo practicaban, aunque hay historiadores que estiman que sus raíces se pueden encontrar en la cultura griega, para quienes el desarrollo del cuerpo era un reflejo de la armonía corporal y física (Lavelle, 1982).

Los años dorados del culturismo en Estados Unidos -en Europa nunca tuvo tantos seguidores- fueron los años 70 y 80, con el nacimiento de todo tipo de concursos, premios, revistas y exhibiciones internacionales, justo en el momento en el que se estaban iniciando las manifestaciones en contra de la Guerra de Vietnam y la gran potencia entraba de lleno en la crisis del petróleo, al tiempo que surgían los movimientos feministas que reivindicaban cambios jurídicos, políticos y sociales para toda la población, pero especialmente para las mujeres. El documental fetiche de esta nueva ola culturista fue Pumping Iron, rodado en 1979 por los directores Robert Fiore $y$ George Butler e interpretada por Arnold Schwarzenegger, Franco Columbu y Lou Ferrigno, el actor que más tarde encarnaría al Incredible Hulk. Esta serie de televisión que estuvo en antena entre 1978-1982, en los Estados Unidos y fue conocida como $L a$ Masa o el Increíble Hulk en los países latinos, cuenta la historia de un hombre que sometido a unas intensas radiaciones obtiene unos poderes sobre naturales y es inmune a cualquier tipo de dolor físico. Lou Ferrigno consiguió varios reconocimientos de la Academia de Televisión Americana y mostró a los espectadores un cuerpo trabajado y musculado que era el temor de todos los que se acercaban a él en los momentos de furia contenida, convirtiéndose en otro súper héroe de acción de la talla de Superman y Spiderman que saltaron del cómic a la pantalla, en un intento de promover la moral y el potencial americano dentro $y$ fuera de las fronteras.

El documental Pumping Iron llevó a la fama a un joven desconocido hasta el momento en los Estados Unidos y de origen 
austriaco llamado Arnold Schwarzenegger, el cual pasaría a encarnar los roles de joven violento $y$ destructivo en el cine de Hollywood de los 70 y 80. Desde Hércules (1970), Conan el Bárbaro (1982) o Conan el Destructor (1984), hasta Exterminador (1984), Depredador (1987) o la trilogía Terminator (1984-1991-2003), se encuentran los mismos elementos narrativos que aparecían en Pumping Iron y que encierra la práctica del culturismo: salud, heterosexualidad, narcisismo, individualismo y temor al otro (al extranjero, al invasor, a lo desconocido, al futuro, etc.). Schwarzenegger es capaz de salvar a la humanidad usando su fuerza, sin necesidad de ayuda de nada ni de nadie - excepto de su potencial físico y de sus armas-, es autónomo $y$ autosuficiente $y$ siempre logra aquello que se propone, por muy difícil que sea. En las películas de Schwarzenegger, la acción y el espectáculo son las claves de su éxito, espectáculo que se pone de manifiesto en las competiciones de bodybuilding: poses agresivas, falta de comunicación entre los participantes que salen como si fuera modelos a punto de ser observados, muy maquillados $y$ desnudos, $y$ a veces con distintivos que recuerdan los símbolos militares. El documental Pumping Iron introduciría, por lo tanto, el germen que después se extendería a otras películas de acción hollywoodienses: autocontrol, competitividad, guerra psicológica $y$ fuerza física $y$ mental.

En el siglo XXI, la práctica de bodybuilding parece haber perdido el éxito que tuvo en otros tiempos en Occidente, pero ha llegado con fuerza a Afganistán. La Federación Nacional de Bodybuildings con sede en Kabul, estima que existen más de mil centros repartidos en todo el país, de los cuales doscientos están en la capital y son de reciente creación. Los principales seguidores son jóvenes de hábitat urbano de entre veinte a treinta años $y$ aunque no todos se inclinan por el desarrollo excesivo del músculo, un alto porcentaje acude regularmente para ejercitarse y participar en los concursos que anualmente organiza la Federación Nacional en el Park Cinema de Kabul, el cine de mayor capacidad en todo el país y en donde se proyectan películas antiguas de Hollywood y Bollywood ${ }^{1}$. La Federación de Bodybuilding en Afganistán fue creada a finales de los 90 e inauguró el primer centro de bodybuilding para mujeres en la región de Parwan en el año 2007, aunque las jóvenes no pueden competir de manera pública. Esta práctica sigue siendo mayoritariamente masculina, de clase mediaalta $y$ hábitat urbano y reservado a una minoritaria élite juvenil.

\section{LOS CARTELES DE BODYBUILDINGS: ¿MÚSCULOS, FORTALEZA Y CAMBIO SOCIAL?}

Los carteles de bodybuildings son una de las representaciones visuales que más se repiten en la capital afgana junto con la publicidad de los salones de boda, de banca y de telefonía móvil (Val, 2010). En un país que ha sufrido más de treinta años de conflicto armado y de guerra civil, la aparición desmedida y repentina de la publicidad exterior desde la llegada de las tropas extranjeras $y$ de las organizaciones $y$ empresas internacionales, no ha dejado indiferente a la población afgana $y$ ha transformado el entorno urbano de la capital.

La película Osama del director Siddiq Barmak sobre la ocupación talibán en los años 90, mostraba un Kabul desértico y gris, con calles y casas de barro destruidas, sin ningún resquicio de desarrollo económico. Kabul es en estos momentos una ciudad que trata de sobrevivir entre los recientes barrios residenciales, los hoteles y los centros comerciales reservados a una élite y los suburbios que crecen sin mesura en las laderas de las montañas y que no gozan de agua corriente ni electricidad (Val, 2011). Los locales para la práctica del bodybuilding se han instalado principalmente en el centro de la ciudad, son un oasis en medio del caos circundante; su tamaño y sus comodidades toallas limpias, aire acondicionado, modernos aparatos deportivos...- dependen del coste de inscripción, que puede rondar entre los diez y los veinte euros al mes, un importe elevado que solo una minoría puede permitirse, si se tiene en cuenta que el sueldo medio de un médico en Kabul no es superior a los cincuenta euros al mes (Mercy, Val y Ziar, 2009). 1 Ver: Afghanistan Bodybuilding Federation <http://
www.abbf.asia/161208.html> 
Durante mi estancia en el país, visité más de veinte establecimientos de culturismo, realicé más de doscientas fotografías y de manera informal entrevisté a jóvenes que estaban realizando entrenamientos en estos centros, como a los afganos con quien trabajaba y que me permitieron comprender el tipo de población que asistía a estos gimnasios. El modelo que ha servido para el análisis de los carteles de bodybuilding va más allá de una simple concepción estética, desde esta perspectiva se comparte el presupuesto de Michel Baxandall, quien llamó "ojo del periodo" a las imágenes referenciales identificativas de cada momento histórico. La producción cultural no podía ser considerada una actividad independiente y autónoma del contexto donde había sido creada, asimismo estaba implicada en actividades tanto económicas como culturales, sociales y políticas (Baxandall, 1972). Siguiendo la misma línea que Baxandall, W.J.T. Mitchell afirma que la "cultura visual" es un campo de estudio multidisciplinar $y$ aunque el autor se centre en el análisis de imágenes artísticas, establece la importancia de las mismas para el estudio de las mentalidades y de los cambios sociales (Mitchell, 1995: 207). Los presupuestos de sociólogos clásicos han sido también de gran ayuda: Marx, Weber y Durkheim estudiaron los procesos sociales desde una perspectiva de cambio, lo que les permitió definir los sistemas sociales como sistemas que sufren transformaciones debido a conflictos, luchas, intereses, desajustes y reajustes del campo social. Desde este planteamiento teórico, los sociólogos Julia Varela y Fernando Álvarez-Uría, ponen de manifiesto en su ensayo Materiales de Sociología del Arte, que las obras de arte o las representaciones visuales son hechos sociales $y$ como tales, presentan una cosmovisión, una visión específica del mundo en el momento que fueron creadas. De esta manera, una lectura sociológica de la imagen debe estar guiada por una problematización y por la aplicación de categorías sociológicas que, al tener en cuenta los procesos históricos, permiten observar las regularidades y las innovaciones, es decir, ver la obra como un espacio social en el que de algún modo estén presentes los códigos que rigen las relaciones sociales (Varela y ÁlvarezUría, 2008). Asimismo, estos autores tratan de esclarecer cómo las representaciones visuales, por ejemplo, encierran significaciones sociales complejas, relaciones de poder y de solidaridad que se llegan a manifestar en la disposición de las figuras en el espacio en el que aparecen representadas, en la gestualidad, la vestimenta, la aparición y repetición de objetos... como en este caso sucede en los carteles presentados en este artículo.

La mayoría de los carteles de bodybuilding son dibujos hechos a mano y solo en ciertas ocasiones - dependiendo del status del local- aparecen fotografías de mayor calidad. En estos carteles siempre encontramos uno o dos jóvenes excesivamente musculados $y$ en posiciones que destacan un cuerpo esculpido y artificial. Michel Foucault en su ensayo Vigilar y Castigar destacó cómo los mecanismos microfísicos del poder se materializan en el cuerpo - tecnología política del cuerpo-e intentó demostrar la manera en la que las relaciones de poder penetran en el interior mismo del cuerpo. La repetición sistemática de un tipo muy definido de carteles como los que se verán más adelante, son un indicio de esa dominación -económica, cultural...- que ha ido penetrando en la cultura afgana en las últimas décadas, pero sobre todo desde la incursión de las tropas militares extranjeras a comienzos del siglo XXI.

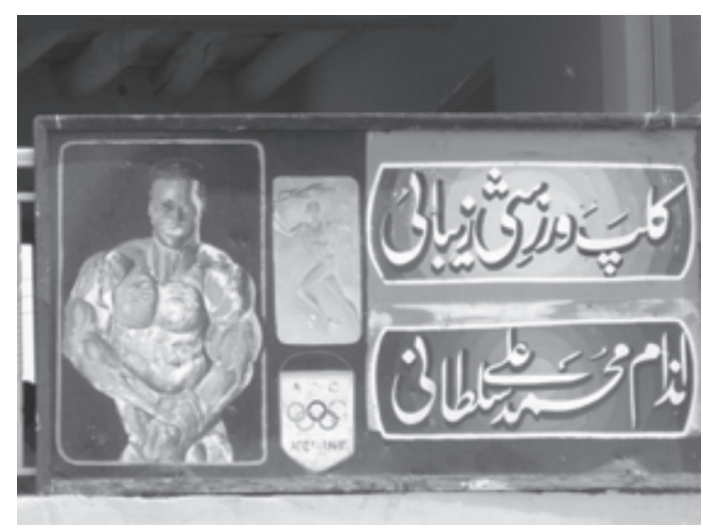

FIGURA 1

OMID JAWAN GYM

Fotografía: Alejandra Val 
En el centro de este cartel se puede ver a un deportista griego que aparentemente ha ganado una prueba atlética porque lleva en sus manos una rama de olivo, símbolo de la victoria. En la parte inferior, se muestran cinco anillos que representan a los Juegos Olímpicos, competición a nivel internacional que se remonta a principios del siglo xx y en la que Afganistán solo ha participado en cinco ocasiones (1936, 1992, 1996, 2004 y 2008), obteniendo su primera medalla en taekwondo en este último año. Los deportes occidentales aparecieron en Afganistán tras las primeras invasiones británicas a finales del siglo XIX e introdujeron el cricket, deporte que se practicó durante décadas. Durante el reinado de Amir Habibullah (1901-1919) se puso de moda el golf y el tenis, asimismo se creó el primer equipo nacional de fútbol, aunque el buzkashi siguió siendo el deporte principal hasta la llegada de los talibanes al poder en 1992, quienes prohibieron cualquier actividad lúdica, ya fuera deportiva, musical o cinematográfica. En este cartel aparece el retrato de un bodybuilder o culturista con el rostro desdibujado y una amplia sonrisa, con cuya postura - brazos hacia delante y torso ladeado- pone en evidencia su musculatura. En la derecha aparece el nombre del establecimiento en dari, una de las lenguas mayoritarias del país y en el centro los símbolos occidentales deportivos por autonomasia.

En los carteles 2 y 3, los hombres representados cubren su cuerpo con una ligera prenda $y$ se adornan con gafas oscuras, botas

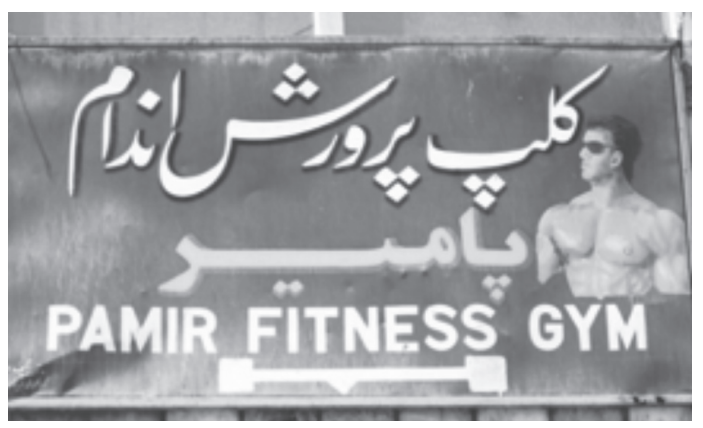

FIGURA 2

PAMIR FITNESS GYM

Fotografía: Alejandra Val

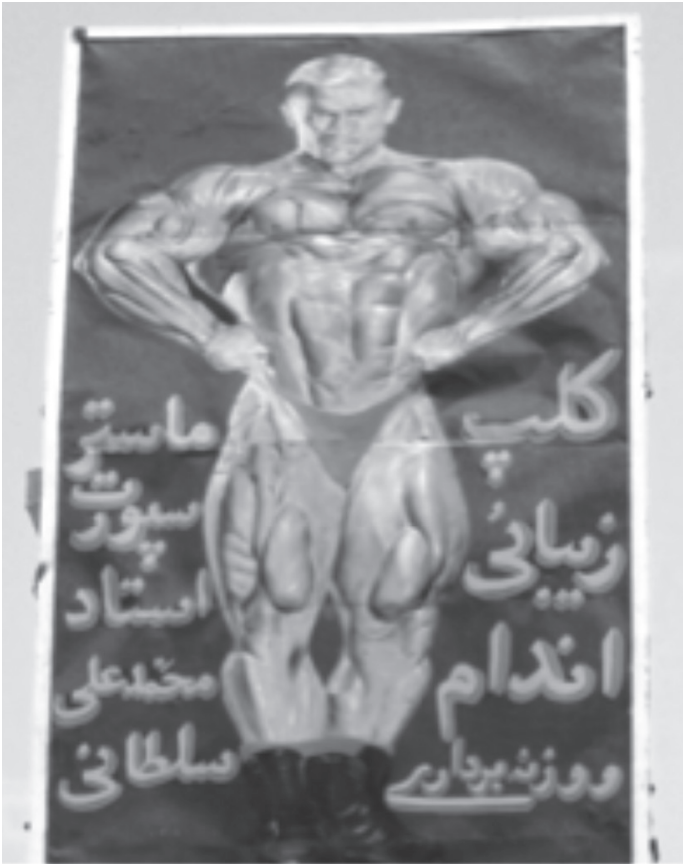

FIGURA 3

MOHAD ALI SULTANI GYM

Fotografía: Alejandra Val

militares y cadenas de oro, con el fin de mostrar su potencia, agresividad, fortaleza y posesiones materiales. En estos carteles, los textos que acompañan a las imágenes están escritos en dari o en pastú - las dos principales lenguas afganas-y también aparecen en inglés, símbolo de la nueva clase media alta afgana que quiere distinguirse como grupo social, ya que hablan y entienden este idioma.

El inglés además de ser la lengua de moda entre los más jóvenes, aquellos que la han aprendido durante su estancia como refugiados en Pakistán, es también la más demandada por las organizaciones internacionales y quienes la dominan, encuentran trabajos mejor remunerados que el resto de la población ${ }^{2}$. A lo largo de mi estancia en el país, pude apreciar que muchos de los jóvenes que trabajan

2 El sueldo de una persona que trabaje en una Organización Internacional suele ser entre los ciento cincuenta a los seiscientos dólares al mes. 
en organismos o instituciones internacionales acuden a estos centros: pueden pagar las altas cuotas de inscripción y son lugares de recogimiento para reunirse entre iguales y cuidar de su cuerpo.

Estos gimnasios son exclusivamente masculinos, su tamaño no es muy amplio y en todos los que pude visitar se venden productos de alimentación ligados a la práctica del culturismo. Otros de los elementos que los identifican son los enormes espejos que cubren las paredes, decoración que se completa con carteles de los rostros más famosos del culturismo en los Estados Unidos o en Pakistán, donde esta práctica también está de moda, como es el caso de Mike Matarazzo, conocido culturista en los 70 en América o Shoaib Zahoor, ícono del culturismo en Asia Central y ganador de las últimas competiciones asiáticas celebradas en marzo de 2010 y 2011.

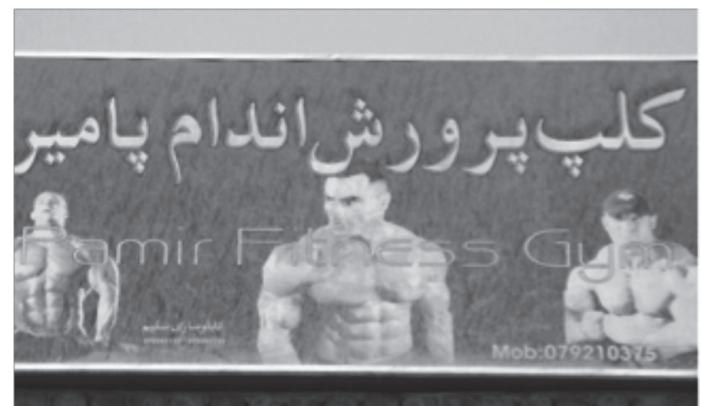

FIGURA 4

PAMIR FITNESS GYM

Fotografía: Alejandra Val

Este cartel no se trata de un dibujo sino de una fotografía. Muestra a tres bodybuilders sin ningún contacto entre ellos y en poses que muestran su potencialidad: con la cabeza hacia arriba, mirando de soslayo y con una mirada frontal y directa. La introducción del número de móvil es significativo en un país donde durante más de tres décadas no hubo ningún tipo de conexión telefónica. En la actualidad, hay más de cinco compañías de telefonía móvil
- la mayoría de capital extranjero- entre las que se encuentran: Roshan, AWCC (Afghan Wireless Communication Corporation), Areeba, Afghan Telecom y Etisalet. En Afganistán, con una población de 22 millones de habitantes, un $7,5 \%$ de los habitantes tiene un teléfono móvil, los principales compradores tienen edades entre

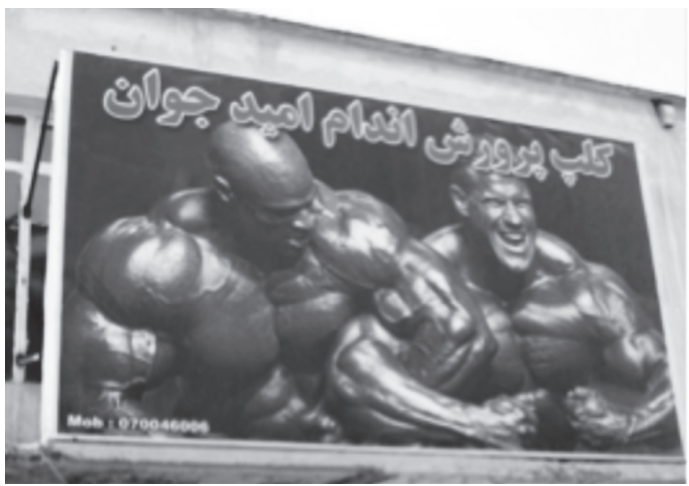

FIGURA 5

MOHD ALI MASTER

Fotografía: Alejandra Val

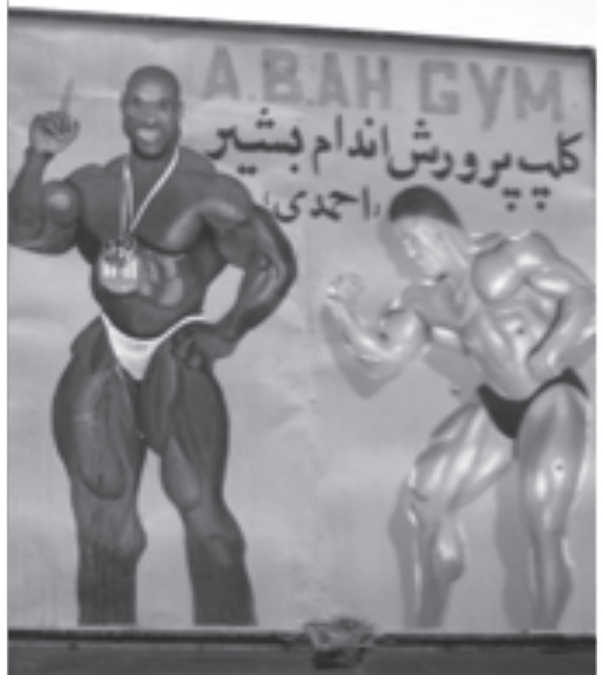

FIGURA 6

BAHIR AHMANDI GYM

Fotografía: Alejandra Val 


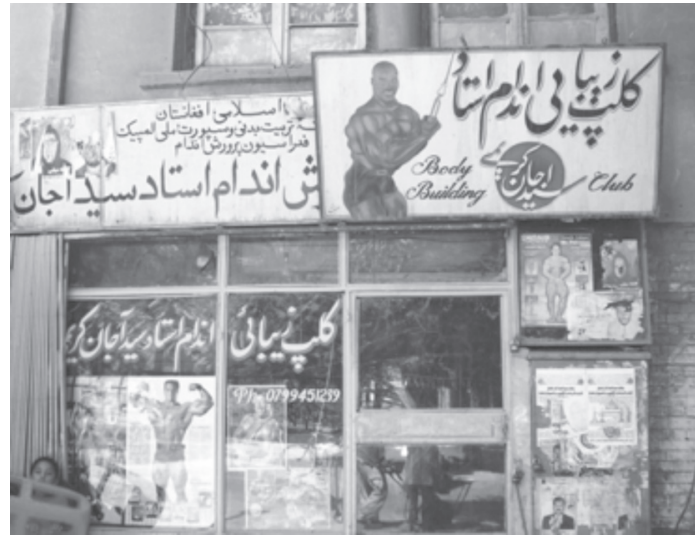

FIGURA 7

SAID AJAN KARIM BODYBUILDING CLUB Fotografía: Alejandra Val

los 25-30 años y residen en las zonas urbanas, asimismo de ese porcentaje, solo un $7 \%$ son mujeres. La posesión y sobre todo el uso de un teléfono es otro distintivo de clase $y$ de un nuevo consumo de ostentación (ALTAI, 2010).

Los carteles $(5,6$ y 7 ) que se van a comentar a continuación también son un tipo de representación que se repite con mucha frecuencia en la publicidad de este tipo de establecimientos y en la que aparecen hombres de color. Yvonne Tasker en su obra Spectacular bodies: gender, genre and the accion cinema, expone que fue a partir de los años 70, cuando los actores negros ganaron terreno como héroes de ficción en el cine norteamericano, aunque normalmente representaban a personajes malvados. La autora especialista en estudios culturales $y$ de cine destaca las actuaciones de Richard Roundtree en Shaft, Melvin Van Peebles en Sweet Sweetback's Baadasssss Song (ambas de 1971) y Ron O`Neal en Superfly (1972), que se pusieron de moda en este momento $y$ que ofrecieron una versión muy agresiva de la masculinidad de este grupo. La presencia de las minorías raciales en el cine americano surgió al mismo tiempo que la aparición de las mujeres heroínas en el cine de Hollywood, en un momento en el que los movimientos feministas pedían una mayor representatividad y presencia pública. Por lo tanto, la industria fílmica no dudo en hacerles protagonistas de sus series y películas, ya que las mujeres y las minorías eran potenciales consumidores, aunque desde el cine comercial su presencia fue muy estereotipada y no suavizó las diferencias sexuales o raciales (Tasker, 1993: 37).

En Afganistán, la presencia de hombres y mujeres de color es inexistente, en el país conviven varias etnias, los más numerosos son los pashtunes, tayikos, hazaras $y$ uzbekos $^{3}$. Los pashtunes son $40 \%$ de la población, los tayikos, musulmanes sunitas, representan alrededor del $25 \%$ de la población y los hazaras, musulmanes chiítas, representan el $19 \%$ de la población afgana. Su lengua es un dialecto del dari, con influencias del turco y del mongol. Los uzbekos, musulmanes sunitas, conforman el 12\% de la población, agrupada en el norte y el oeste del país, en los dos lados de la frontera con Uzbekistán. El buzkashi, se señaló anteriormente, no es solo una práctica deportiva sino que durante décadas ha servido para reunir a distintos grupos étnicos y tribales, $y$ celebrar fiestas entorno al espectáculo.

En este panorama multiétnico es interesante destacar que en los carteles de los bodybuiding no aparecen representados las diferentes etnias afganas — que tienen rasgos físicos muy específicos como los hazaras, de origen mongol-y sin embargo, aparecen hombres de color o personajes con rasgos occidentales - la piel y el pelo rubio. La hipótesis se plantea es que en la aparición de este tipo de carteles con personas de color, tiene que ver (entre otros aspectos) con la presencia de las fuerzas armadas, principalmente americanas, desde el año 2001 (fecha en la que empezaron a aparecer este tipo de representaciones) porque aunque no existan datos oficiales, se estima que un tercio de los militares americanos en misiones extranjeras son de origen latino o africano.

3 Los grupos minoritarios son los aimaks, baluchis, braouis y nuristanis, entre otros. 


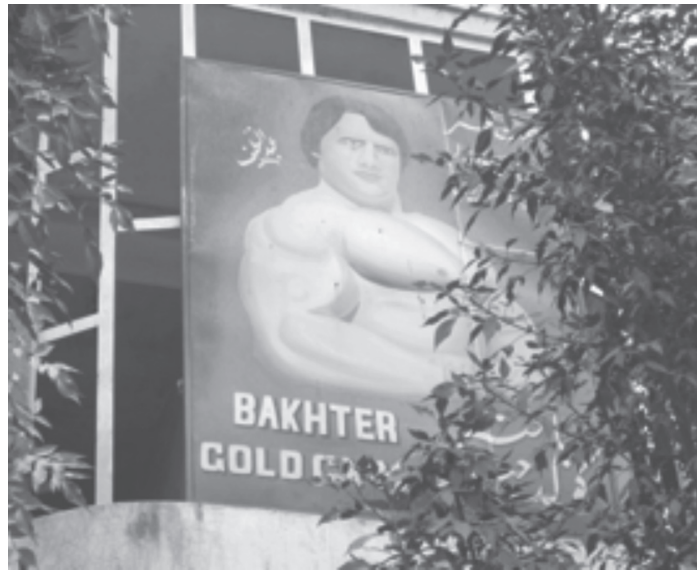

FIGURA 8

BAKHATAR GYM

Fotografía: Alejandra Val

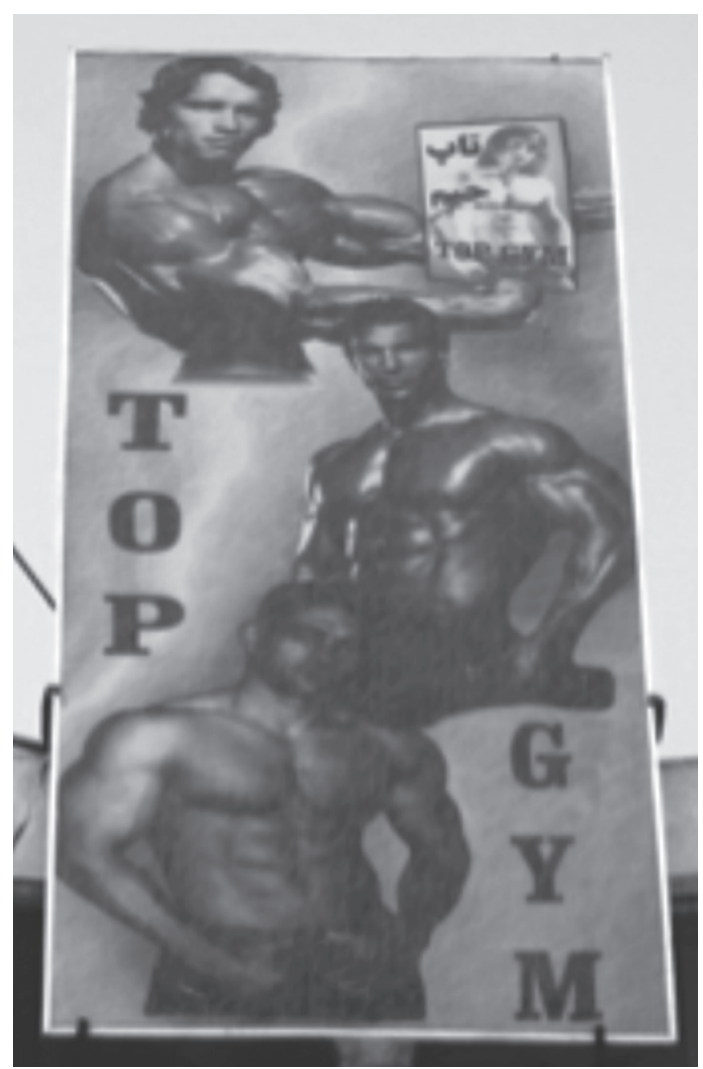

FIGURA 9

DEDIQULLAH SHIRZI BODY BUILDING Fotografía: Alejandra Val

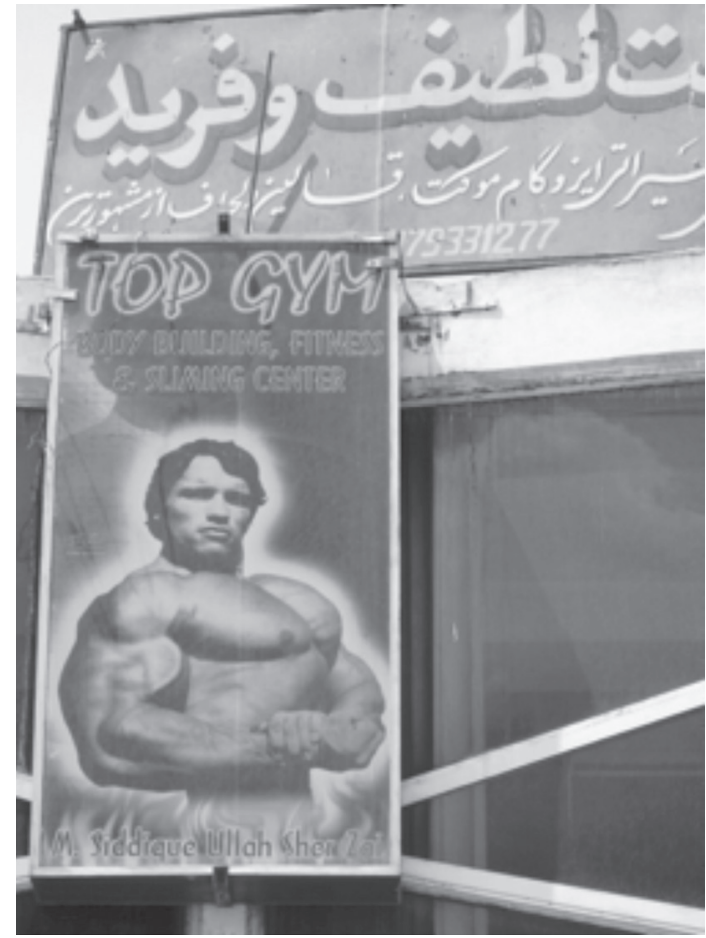

FIGURA 10

TOP GYM

Fotografía: Alejandra Val

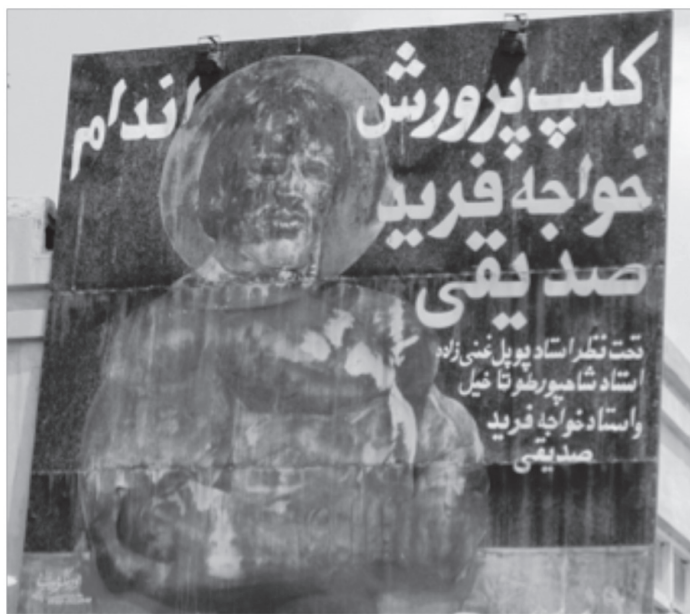

FIGURA 11

KHAWAJ FARID SIDIQUI GYM

Fotografía: Alejandra Val 
Los carteles que se repiten con más frecuencia son aquellos en los que aparecen las figuras de dos rostros cinematográficos muy conocidos a nivel internacional por su participación en películas de Hollywood. Este es el caso de Arnold Schwarzenegger, retratado en su juventud cuando era uno de los íconos de la práctica del culturismo en los Estados Unidos, así como, Sylvester Stallone quien se hizo famoso por la saga de Rambo. Estos dos actores encarnan el sueño americano. Schwarzenegger procedía de una familia austriaca y sin recursos, emigró a Estados Unidos a finales de los 60 para trabajar de albañil y finalmente, se convirtió en un actor de éxito, empresario y hombre político con cargos importantes en el Estado de California. Sylvester Stallone nacido en un pueblo de Nueva York, escribió el guión de la película que le llevaría a la fama: Rocky en 1976 y con la que conseguiría su único Oscar. Ha protagonizado más de veinte películas de acción y al igual que Schwarzenegger, es en la actualidad un reconocido hombre de negocios. La última película de toda la saga Rambo III, estrenada el 25 de mayo de 1988, cuenta de manera muy violenta la misión de Stallone para proveer cohetes $y$ armas a los afganos en su lucha contra el invasor, que no es otro que el ejército soviético y en donde Massoud - líder de los muyahidines - agradece la ayuda y la cooperación americana ${ }^{4}$. Esta película también recoge un partido de buzkashi, aunque ridiculiza esta actividad al presentarla como bárbara y propia de un pueblo salvaje.

Las imágenes de estos dos actores están presentes en casi todos los centros de musculación que visité; asimismo, sus películas $y$ sus hazañas son conocidas entre aquellos que practican este deporte. Su fama hizo que el primer establecimiento de bodybuilding en Kabul: el Gold's Gym, hiciera referencia a uno de los enclaves de culturismo en Estados Unidos, el cual fue el lugar elegido para ser el

4 Los Muyahidines o guerreros sagrados se enfrentaron al gobierno soviético y a los talibanes. En numerosas regiones del país también hubo enfrentamientos entre las distintas fracciones o partidos políticos (Tanzim) de Muyahidines, lo que ocasionó la muerte y destrucción de muchos pueblos. escenario principal del documental Pumping Iron y que encumbró a Schwarzenegger a partir de esta fecha.

Las películas y series de televisión que llegan a la población afgana proceden principalmente de Hollywood y Bollywood. El cine afgano es prácticamente inexistente $y$ las pocas películas realizadas en los últimos diez años han sido coproducciones, como sucedió en el caso de la taquillera Osama (2003) que cuenta la historia de una niña que se disfraza de joven para poder trabajar. Durante la ocupación de la Unión Soviética de 1978 a 1986, el cine sirvió como medio de propaganda política y los intercambios culturales entre los dos países se intensificaron, pero a partir de los 90 fue progresiva la entrada de películas americanas e indias de serie B en el panorama audiovisual afgano. En la actualidad, los cinco cines que siguen abiertos en Kabul - los cines: Park, Timor Shahi, Baharestan, Khirkhana y el Ariana Cinema - proyectan copias en mal estado de viejas películas de Hollywood $y$ Bollywood, siendo las principales las películas de acción. Los héroes desprestigiados de Occidente pueblan los bazares de las principales ciudades afganas donde es muy fácil encontrar las películas de combate de los antiguos íconos americanos, convertidos en los nuevos íconos afganos.

\section{DESPLAZAMIENTO Y RETORNO}

Tras las entrevistas informales que se realizaron durante la estancia en el país, se pudo constatar que la mayoría de los jóvenes que asisten a los centros de bodybuildings en Kabul, han regresado a su país en las dos últimas décadas. Los años de conflicto que ha sufrido la población afgana alentó los desplazamientos de sus habitantes fuera de las fronteras. La primera ola migratoria se produjo en 1970, debido a los años de sequía, haciendo que una gran parte de la población emigrara a Irán y a Pakistán. Irán abrió sus puertas a la población afgana ofreciendo trabajos en el sector del petróleo y de la construcción. Pakistán acogió a miles de afganos en los campos de refugiados, proceso migratorio que se acentuaría durante la invasión soviética a 
finales de los 70. Los afganos que emigraron a Pakistán eran principalmente de hábitat rural y se establecieron en las zonas pastunes; los años vividos en los campos de refugiados - había más de trescientos- hicieron de estos asentamientos focos de muyahidines $y$ fundamentalistas cuyas consecuencias se harían patentes años más tarde. En Irán, por el contrario, solo el 3\% de los afganos se establecieron en los campos de refugiados, el resto eligió los principales núcleos urbanos (UNHCR, 2012).

En Teherán, así como en otras ciudades iraníes, los más jóvenes pudieron ir a la escuela $y$ aprender un oficio; no obstante, las autoridades restringieron el número de profesiones, dedicándose principalmente a labores de construcción y agricultura. En el año 1992 y según datos de la Agencia de Refugiados de las Naciones Unidas, más de seis millones de personas - lo que correspondería al 20\% de la población- habían abandonado el país para regresar en 1992 y en 2002, año en el que aproximadamente cinco millones y medio de afganos regresaron de Pakistán e Irán a Afganistán (UNHCR, 2011). En la actualidad, los afganos están dispersos en más de 72 países, aunque el $96 \%$ de los desplazados viven en los países vecinos y es muy difícil saber en qué proporción se han asentado de manera estable en Afganistán (Saito, 2009: 11). Uno de los últimos estudios llevado a cabo por la Comisión de Refugiados de Naciones Unidas señaló que para la mitad de los entrevistados afganos, el regreso a su país de origen no había cubierto todas sus expectativas por la dificultad de encontrar trabajo, vivienda y ciertos servicios mínimos como el agua o la electricidad, además señalaban que las mayores dificultades las habían tenido sus hijos, al volver a un país del que solo habían oído hablar con nostalgia y del que no se sentían identificados (AIHRC, 2007: 15).

Esta generación que tiene entre 20-30 años ha nacido $y$ se ha criado en el extranjero, incorporado nuevos hábitos y maneras de relacionarse que no comparten con sus padres y abuelos. Según Homa Hoodfar, los roles de género entre los refugiados afganos residentes en Irán se han transformado en varios aspec- tos: participan en mayor medida en actividades fuera del hogar, las mujeres suelen tener más poder de decisión en temas como el matrimonio, la salud, la educación de sus hijos, etc., lo que provoca conflictos intergeneracionales $y$ desajustes sociales (Hoodfar, 2004). Por ello, los jóvenes que pudieron estudiar y aprender ciertas habilidades como inglés o informática $y$ trabajan para organizaciones internacionales y empresas extranjeras, buscan nuevas alternativas de consumo y de ocio que están presentes en su forma de vestir - abandonando prendas tradicionales como el salwar camise e incorporando el cuero, los vaqueros, las prendas sintéticas... - y de relacionarse. En este horizonte de cambio y transformación social, los centros de bodybuildings les permiten reunirse en un lugar aparentemente seguro y quizás soñar con un futuro mejor que pasa por el cuidado meticuloso $y$ a veces obsesivo del cuerpo, sin darse cuenta que la cultura que gira alrededor a la práctica de este deporte es muy conservadora (Klein, 1986: 4).

Actualmente, uno de los graves problemas de los jóvenes afganos es la adicción cada vez mayor - a las drogas. Afganistán es el primer país productor de opio y heroína, dicha producción ha influido en el nivel de consumo. Un estudio nacional llevado a cabo por la United Nation Office on Drugs and Crime (UNODC) en el año 2005, destacó el aumento significativo del uso de los psicotrópicos consumidos sin ningún tipo de receta médica $y$ vendidos de manera ilegal para aliviar síntomas como la depresión, la ansiedad, los desórdenes de sueño o los desórdenes debidos al estrés (MacDonald, 2008). Los jóvenes afganos encuentran con relativa facilidad estas sustancias y existen varios casos de culturistas afganos fallecidos por ingerir anabolizantes de dudoso origen junto con la mezcla de otras drogas, con el fin de aumentar su musculatura y ser capaces de continuar con su riguroso entrenamiento (MacDonald, 2008).

\section{REFLEXIONES FINALES}

La población afgana no es dada a mostrar su cuerpo en público; sin embargo, hay un espacio en el que la desnudez es sinónimo de 
bienestar y purificación, siendo este los baños públicos. En estos baños es muy común encontrar a familias de mujeres - abuelas, hijas, nietas - o de hombres dedicándose al cuidado del cuerpo con esmero y detenimiento: un lugar para lavarse, peinarse $y$ depilarse, en donde los más mayores masajean los cuerpos de los más jóvenes. El contraste se produce cuando las mismas mujeres que han estado durante horas desnudas en los austeros baños se cubren con el burka para salir al exterior. Los hombres hacen lo propio vistiendo un salwar camise o traje compuesto por dos piezas de algodón, generalmente de color oscuro, cuya camisa cubre el torso y llega hasta las rodillas. Los baños son lugares muy sencillos si los comparamos con los centros de bodybuildings, donde no solo se practica deporte sino que se venden productos que incrementan la musculatura, alimentos ajenos a la dieta afgana y que son difíciles de conseguir por su elevado precio.

La proliferación de los centros de culturismo para hombres en Kabul, es un ejemplo del creciente interés del culto al cuerpo y de una cierta concepción individualista y narcisista del individuo, en los que además se rompen ciertos tabúes relacionados con el cuerpo masculino. Los años en el exilio que han sufrido la mayor parte de los afganos desde los años 70 $y$ en diversas olas hasta finales de los 90 , han erosionado los sentimientos de unidad nacional y los más jóvenes sienten la necesidad de buscar nuevas prácticas ligadas al ocio y al consumo que den sentido a su vida cotidiana, lo cual conduce al fortalecimiento del cuerpo, quizá como manera de protegerse de un violento pasado $y$ de un futuro incierto $y$ nada prometedor. La aparición de estos locales anuncia el germen de un nuevo tipo de sociedad que trata de combinar las tradiciones del pueblo afgano con las ideas, productos y servicios llegados desde el exterior, principalmente de Irán y Pakistán, pero también de Europa y de Estados Unidos.

En este contexto de cambio y transformación social resulta paradójico que los grandes íconos de la práctica del culturismo en los Estados Unidos y que adornan la mayoría de los gimnasios en Afganistán, sean los actores más destacados de los patrones neoliberales americanos. Por una parte, los jóvenes afganos emulan a las estrellas de Hollywood y de Bollywood que ven en la televisión y en el cine, al tiempo que critican a las fuerzas extranjeras por su ineficacia e inoperancia. En un país donde la mayoría de la población no supera los 30 años de edad, los más jóvenes han tenido que renegociar las contradicciones de su retorno a un país del que desconocen casi todo: el contacto directo con otras realidades y estilos de vida han modificado su manera de comprar y de consumir, otorgando cada vez mayor importancia a la imagen. Estos cambios se aprecian de una manera más significativa en el caso de los hombres, son ellos los que realizan la mayoría de las compras en mercados y bazares al gestionar los ingresos de toda la familia y son ellos en los que recae la protección de la comunidad, una comunidad como se ha mencionado anteriormente, erosionada tras más de 30 años de conflicto armado.

La proliferación de los carteles de bodybuildings muestran las transformaciones que están ocurriendo en esta región de Asia Central, en estos carteles se entrelazan y se complementan registros $y$ códigos provenientes de distintos campos: audiovisual, literario, imaginario e incluso, político (Batenson, 1994) que inciden en el mismo aspecto: frente al aislamiento (control), frente al desarme (defensa) y frente a lo colectivo (refugio individual). Afganistán sigue siendo uno de los lugares más pobres del mundo, las diferencias de género, la falta de oportunidades laborales, la permanencia talibán en muchas zonas y la criticada presencia occidental, junto con el crecimiento de la producción del opio, amenazan permanentemente la estabilidad y la calma social.

Por el momento, las montañas del Hindu Kush que atraviesan el país de norte a sur, son aún lugares vírgenes e indómitos, quizás en pocos años los carteles publicitarios de bodybuildings adornen sus laderas. Esperemos que no sea así, aunque quizá eso signifique que la calma ha llegado por fin a la población afgana; mientras tanto los poderosos medios de comunicación hacen negocio con programas como Afghan Star - copia exacta de American Idol- que reunió a más de 2000 participantes 
en su última edición en la primavera de 2011 y alcanzó un índice de audiencia de once millones de telespectadores en la cadena Tolo TV, que publicitaba el concurso como "una manera de estimular a los jóvenes a dejar las armas y amar la música, un programa democrático y sin censura donde todos podían participar y votar libremente a través del teléfono móvil"5. Un programa para olvidar la tragedia de este pueblo que parece no tener fin preciso.

\section{BIBLIOGRAFÍA}

Alonso, L.E. La era del consumo. Madrid: Siglo XXI, 2006.

altai consulting. Afghan Media in 2010. Synthesis Report. 2010. En: <http://www. altaiconsulting.com/docs/media/2010/ Afghan\%20Media\%20in\%202010.pdf> (consultado el 10 de marzo de 2011).

Afghanistan Independent Human Rights Commission-AIHrc. Annual Report. Kabul: AIHRC, 2007.

Azoy, Whitney. Buzkashi. Game and power in Afghanistan. Pennsylvania: University of Pennsylvania, 1985.

Badinter, E. XY La identidad masculina. Madrid: Alianza Editorial, 1993.

Baxandall, M. Painting and experience in Fifteenth-Century, Italy. Oxford: Clarendon Press, 1972.

Batenson, G. La nueva comunicación. Barcelona: Kairós, 1994.

Bourdieu, P. La distinción. Criterios y bases sociales del gusto. Madrid: Taurus, 1988.

De Mercey, Philibert; Val Cubero, Alejandra y Ziar, Najibullah. "Understanding freedom, democracy and growth form the bottom-up". Moving Out of Poverty. National Synthesis Report-Afghanistan. World Bank, 2006 . En: <http://siteresources. worldbank.org/INTMOVOUTPOV/ Resources/21042151187710751691/AFG_ NSR_final.pdf>

5 Tolo TV forma parte de Moby Group, una joint venture con News Corporation, propietaria entre otros medios del Wall Street Journal.
Fanjul, C. Vigorexia: una mirada desde la publicidad. Madrid: Fragua, 2008.

Foucault, M. Vigilar y castigar. Nacimiento de la prisión. Barcelona: Siglo XXI, 1996.

Fueyo Gutiérrez, A. De exóticos y miserias diversas: publicidad y (re)construcción del imaginario colectivo sobre el sur. Barcelona: Icaria, 2002.

Hoodfar, H. "Families on the move: the changing role of afghan refugee women in Iran". Journal of Women of the Middle East and the Islamic World 2. 2004: 141-171.

Klein, A. Little big men: bodybuilding subculture and gender construction. Albany: New York Press, 1993.

Klein, A. "Pumping irony: crisis and contradiction in bodybuilding". Sociology of Sport Journal 3. 1986: 112133.

Lavelle, Gordon. Bodybuilding: an illustrated history. New York: Arco Publishing, 1982.

Lipovetsky, G. La felicidad paradójica: ensayo sobre la sociedad de hiperconsumo. Barcelona: Anagrama, 2007.

MacDonald, David. Afghanistan's hidden drug problem: the misuse of psychotropics. Kabul: AREU, 2008.

Mercey, Philibert; Val, Alejandra y Ziar, Najibullah. Moving Out of Poverty: Country Report Afghanistan. World Bank, 2009. En: <http://siteresources. worldbank.org / IN TMOVOUTPOV/ Resources/2104215-1187710751691/AFG_ NSR_final.pdf>

Michell, W.J.T. "What is visual culture?". Meaning in the visual arts. Views from the outside: a centennial commemoration of Erwin Panofsky (1892-1968). Irving, Lavi (ed.). Princenton. Institute for Advanced Study, 1995: 207-217.

Parra, P. y Val Cubero, A. "El papel del investigador occidental en el estudio del Otro: trabajo de campo en tres provincias de Afganistán". Actas del XII Congreso Nacional de Sociología en Castilla-La Mancha. Facultad de Ciencias Sociales 
y Jurídicas de Castilla-La Mancha, 2007: 425-436.

Saito, M. Searching for my homeland: dilemmas between borders. Experiences of young afghan returning "home" from Pakistan and Iran. Kabul: AREU, 2009.

Schetter, C. "Ethnoscapes, national territorialization and the afghan war". Geopolitics 10. 2005: 50-75.

Shalizi, H. Afghans pay the price for flexing their muscles. 2010. En: <http:// uk.reuters. com/article/2010/07/23/ us - afghanistan-bodybuilders idUKTRE66M0TZ20100723> (consultado el 15 de febrero de 2011).

Tasker, Y. Spectacular bodies: gender, genre and the accion cinema. London: Roudledge, 1993.

The United Nations Refugee Agency. Finding durable solutions for refugees and displacement for the Islamic Republic of Afghanistan. Kabul: UNHCR, 2011. En: <http://www.unhcr.org/ pages/49e45af26.html> (consultado el 10 de marzo de 2011).
The United Nations Refugee Agency. Country Operations Profile-Afghanistan. Kabul: UNHCR, 2012. En: <http://www.unhcr.org/ cgibin $/$ texis/vtx/page?page $=49 \mathrm{e} 486 \mathrm{eb} 6>$ (consultado el $1^{\circ}$ de marzo de 2012).

Val Cubero, A. "Navegando sin rumbo fijo: jóvenes afganos, matrimonios y poder de decisión. Estudio de caso en cuatro provincias afganas". Praxis Sociológica 14. 2010: 101-115.

Val Cubero, A. "Entre las laderas del Hindu Kush: Kabul como escenario de la película Osama”. Archivos de la Filmoteca 67. 2011: 96-109.

Varela, J. y Álvarez-Uría, F. Sujetos frágiles. Madrid: Fondo de Cultura Económica, 1989.

Varela, J. y Álvarez-Uría, F. Materiales de Sociología del Arte. Barcelona: Siglo XXI, 2008.

Fecha de ingreso: 06/12/2011 Fecha de aprobación: 07/03/2012 
